\title{
Evaluation of ACCURACY OF Five-Axis CNC Milling MaChINe ON THE BaSis OF Test Piece Machining
}

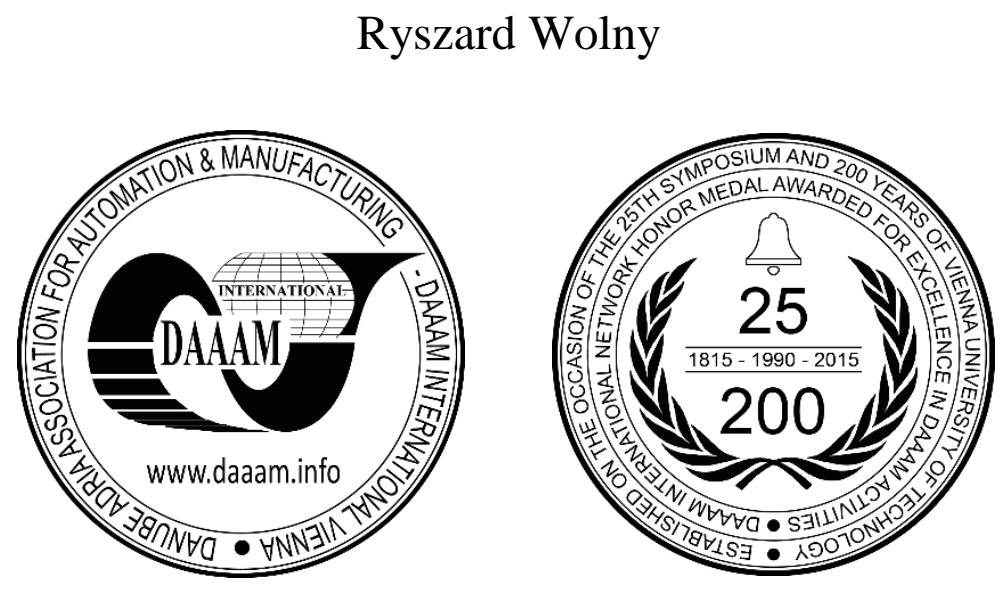

This Publication has to be referred as: Wolny, R[yszard] (2018). Evaluation of Accuracy of Five-Axis CNC Milling Machine on the Basis of Test Piece Machining, Proceedings of the 29th DAAAM International Symposium, pp.01640168, B. Katalinic (Ed.), Published by DAAAM International, ISBN 978-3-902734-20-4, ISSN 1726-9679, Vienna, Austria

DOI: $10.2507 / 29$ th.daaam.proceedings.023

\begin{abstract}
The test piece of cone frustum shape for the evaluation of accuracy of five-axis CNC milling machine was proposed. Machining of the cone surface was made at three angular positions of the test piece on the machine table. Dimensional accuracy of the test piece was evaluated by the measurement of circular form on the Coordinate Measuring Machine (CMM). The obtained results indicate that the accuracy of a milling machine can be assessed indirectly with the use of the described method.
\end{abstract}

Keywords: five-axis milling machine; test piece; accuracy test; circular of cone

\section{Introduction}

Recently, a high demand for the use of five-axis milling centers in the machine industry has been observed. Despite this, the standard for assessing their accuracy has not yet been fully elaborated. The most important tasks of a machine tool include the cutting process. The implementation of the test piece is the basic test indirectly evaluating the geometric accuracy and the positioning accuracy of the machine. In addition, many factors that change the accuracy of machining of the test piece should be taken into account in the conducted research.

The paper proposes a cone frustum as a test piece which undergoes finishing milling at three angular positions in the working space of the machine tool. Accuracy of its execution, through circular measurements, was checked on a coordinate measuring machine.

\section{Current standards for machining of test pieces}

One of the first tests of the accuracy of five-axis milling machine tools was the NAS 979, developed 49 years ago [1], in which the chapter 4.3.3.8.1 presents the test piece in the shape of a cone frustum and the test conditions (Fig. 1). In practice, both manufacturers of machine tools and their users perform finishing machining of the cone frustum, determining their own test conditions. Because the method described in the NAS 979 has become the most popular worldwide, it will probably be further modified and likely introduced as a new standard. 


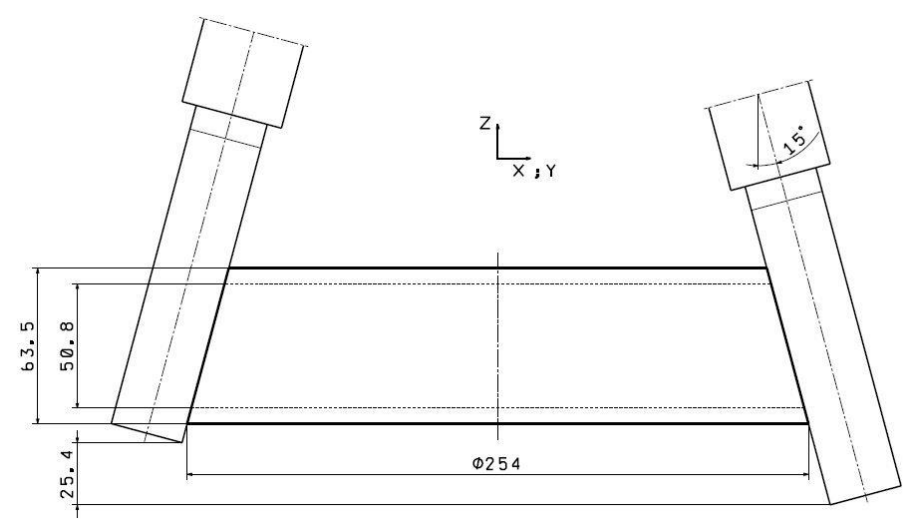

Fig. 1. Diagram of the NAS 979 cone frustum cutting test

The ISO 10791-7 standard was established in 1998 and consists of two machining tests [2]. The first one is a test of making a complex test piece using end mill cutter (Fig. 2). The second is a flat surface machining test performed by face milling. Since 2009, efforts are being made towards the correction of the standard by designing a new test piece for the purpose of testing five-axis machine tools.

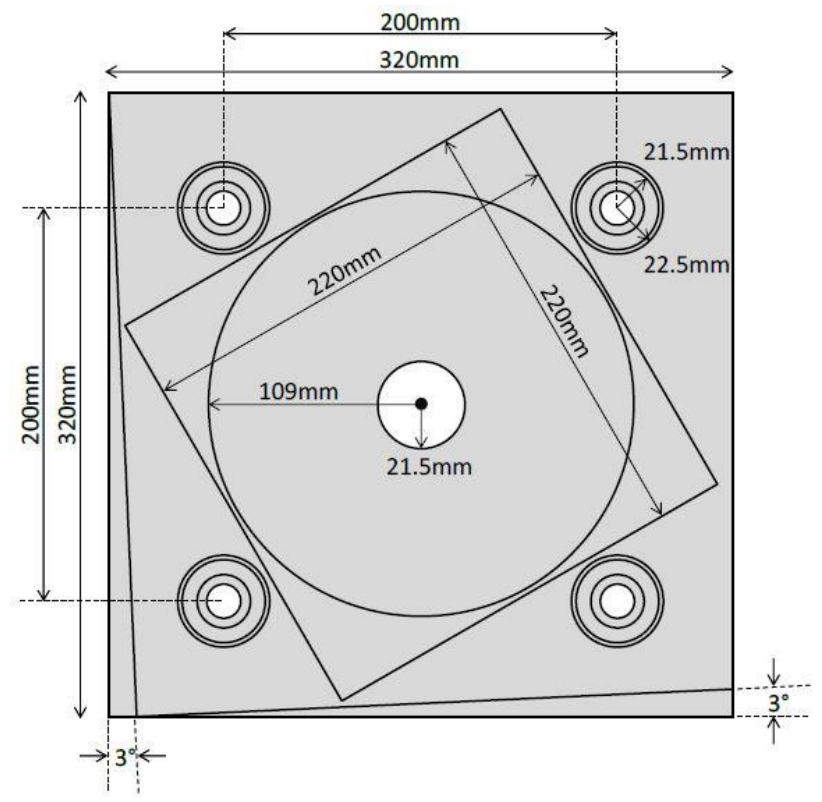

Fig. 2. Complex test piece in ISO 10791-7

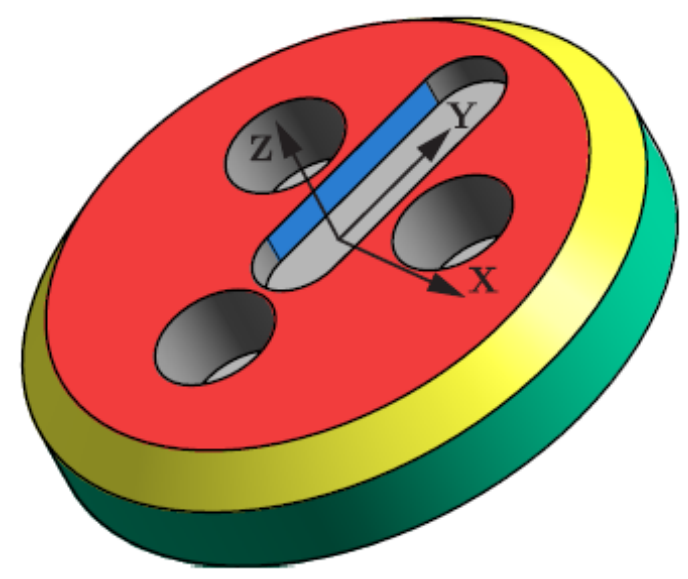

Fig. 3. The test piece proposed in the paper [3] 
In the PhD thesis by Bossoni [3], a new test piece was proposed (Fig. 3), which afterwards was the basis of the modification of the ISO standard [4]. The test piece was intended to be machined without prespecified location and orientation. Other proposals for the use of machining of test pieces to evaluate the accuracy of machine tools are presented in [5], [6], [7], [8].

\section{Control test evaluating the accuracy of the machine tool}

The milling machining center DMU 60 monoBLOCK was used for the tests. The machine tool, purchased in 2010, was operated in a modern industrial plant in a 3-shift system [9]. A milling machine was equipped with a rotary table and a tilting head fulfilling the five-axis machining criteria (Fig. 4).
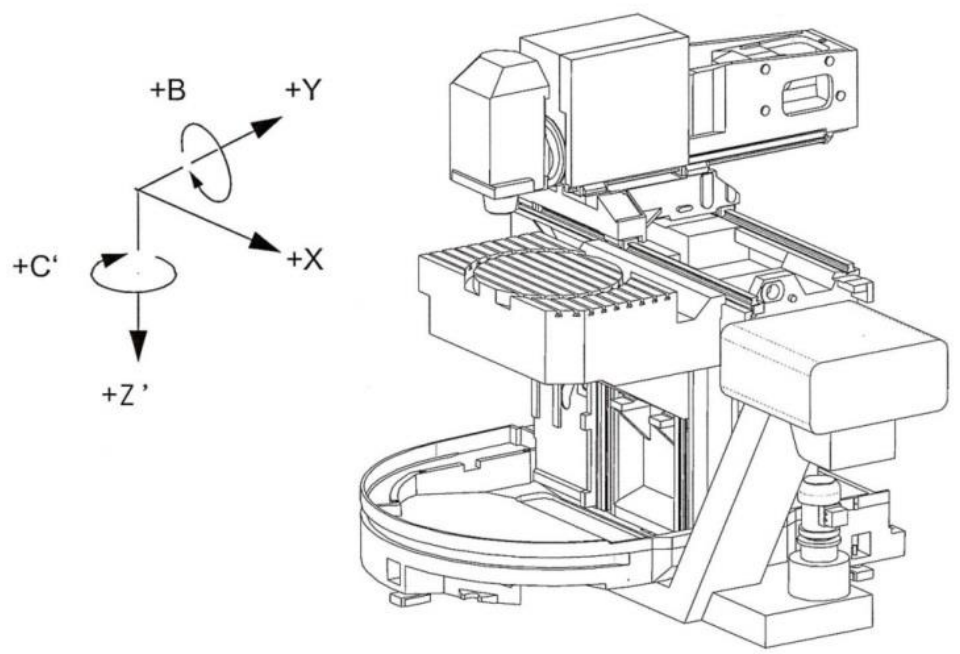

Fig. 4. Machining center DMU 60 monoBLOCK

During the test, the machine tool milled the cone frustum test piece, placed at an angle to the surface of the rotary table. The test piece was pre-machined, with the allowance for finishing milling, on a separate machine tool. Additionally, the custom-made base for the precise location and fixing of test pieces have been prepared (Fig. 5).

The test was carried out at three values of the angle of inclination of test pieces to the machine table: $\varphi=0^{\circ} ; \varphi=15^{\circ}$ and $\varphi=45^{\circ}$. Two test pieces were machined for a each angular position. One in the clockwise (+) direction and the other in the counter-clockwise (-) direction.

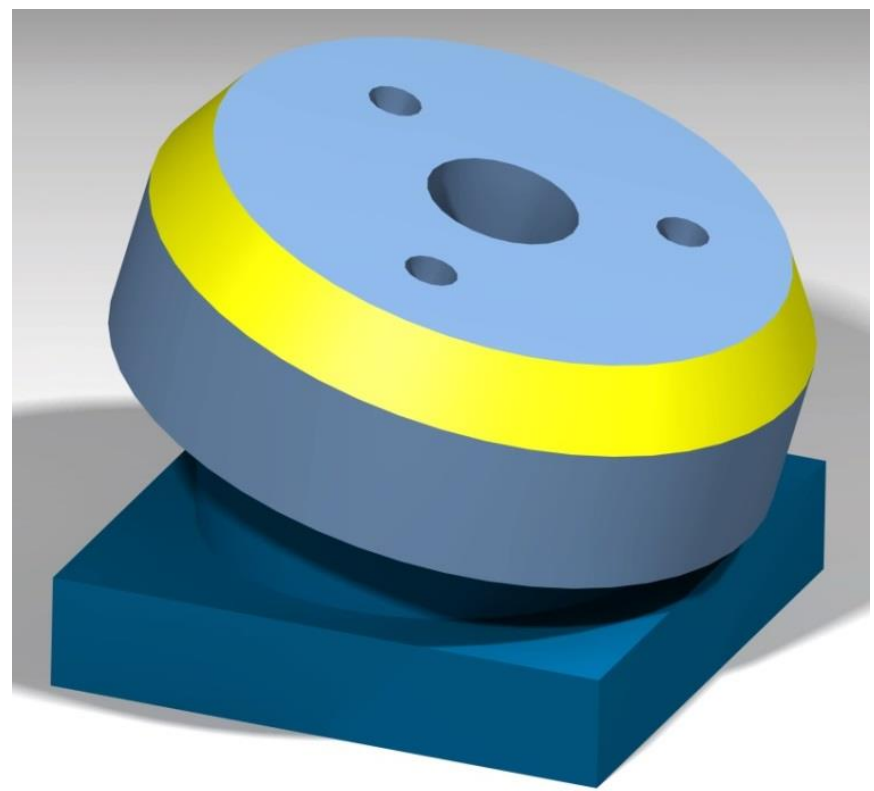

Fig. 5. The model of the test piece with the custom-made base 
For the finishing of the test conical surface, a monolithic tool in the form of a VHM sintered carbide milling cutter with a PVD coating, designed for machining aluminum alloys and plastics, was used. A milling cutter with a working diameter of $\varnothing=20 \mathrm{~mm}$ had 4 blades with an angle of $\lambda=45^{\circ}$ and a total length of $1=150 \mathrm{~mm}$.

The test pieces were made of aluminum alloy. The final milling was carried out in two passes at the spindle speed $\mathrm{n}=5500 \mathrm{~min}^{-1}$ and the "conservative" feed value $\mathrm{v}_{\mathrm{f}}=250 \mathrm{~mm} / \mathrm{min}$.

Figure 6 shows the machining of the test piece on a five-axis milling machine at a tilt angle $\varphi=15^{\circ}$.

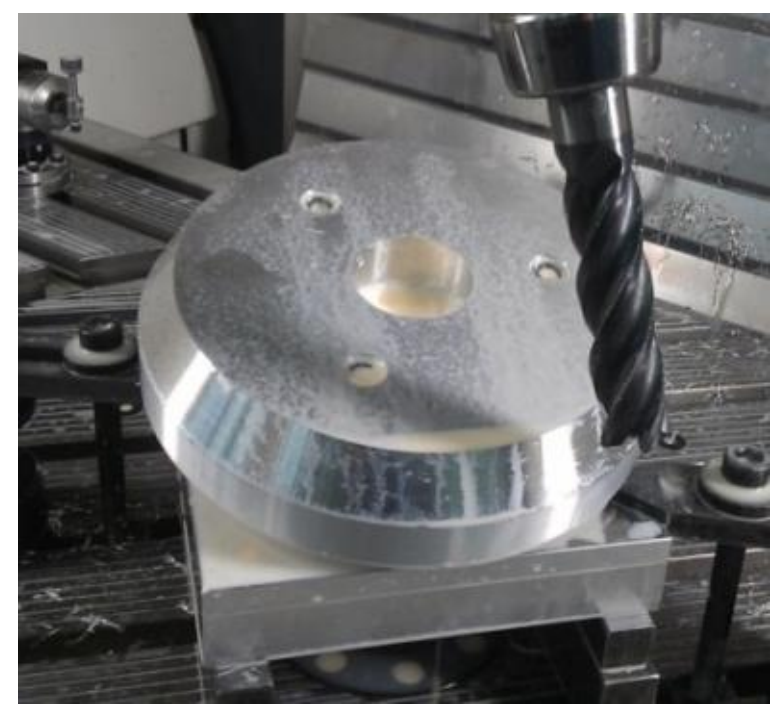

Fig. 6. Machining of the test piece [9]

The accuracy of the test pieces was checked on a Nikon coordinate measuring machine model LK V 15.10.8 using the CMM-Manager software [9]. Measurements of the circularity of machined conical surfaces were scanned in a contact manner with a spindle with a ball diameter of $\varnothing=4 \mathrm{~mm}$ at three measuring heights: $\mathrm{z}=2 \mathrm{~mm} ; \mathrm{z}=10 \mathrm{~mm}$ and $\mathrm{z}=18 \mathrm{~mm}$, starting from the top surface of the cone (Fig. 7).

The circular error for all machined test pieces was determined as the difference between the maximum and the minimum radius deviation in a given measuring circle. According to the NAS 979 standard [1], the calculations taken into account the values at points spaced every $30^{\circ}$ from the intersection of the $\mathrm{X}$ axis with the tested circle.

For a test piece inclined by an angle $\varphi=15^{\circ}$ to the milling table, the average circular error was $0.012 \mathrm{~mm}$. With a slope of $\varphi=45^{\circ}$, the circular error increased to $0.027 \mathrm{~mm}$. The reference value was the position of the test piece for the angle $\varphi=0^{\circ}$, where the circular error was $0.008 \mathrm{~mm}$.

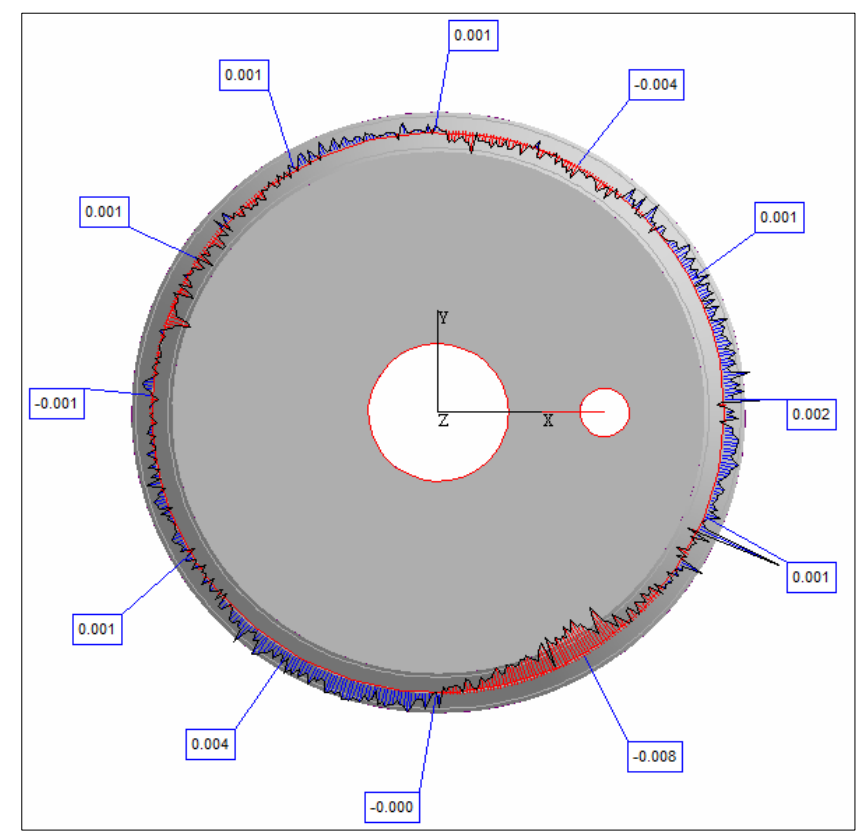

Fig. 7. The results of the test piece scanning [9] for $\varphi=15^{\circ}(+)$ 
Figure 7 shows a graphical report of the scan results for the inner measuring circle and the angle $\varphi=15^{\circ}(+)$. All the graphs show repetitive "peaks" and periodic changes of the amplitude of the measurement results, which warrant further examination. It was sometimes possible to observe the characteristic points of contact between the cutter and the work piece at the beginning and end of the milled conical surface.

Some new measurement strategies of 3D rotary elements and spherical machine parts were described in the scientific papers [11], [12].

\section{Conclusion}

The finishing of the test piece in the shape of a cone frustum indirectly determines the accuracy of a five-axis CNC milling machine. The dimensional accuracy of the test piece was determined by measuring the circular error on the coordinate measuring machine. The tests confirmed that the location and orientation of the test piece in the working space of the machine tool affects its accuracy. It should be noted that the result of the control test the five-axis machining center depends on the knowledge and skills of the programmer, operator and controller. Therefore, it should be considered whether such a test can be regarded as a standard.

\section{References}

[1] NAS 979. (1969). Uniform Cutting Test - NAS Series Metal Cutting Specification, Aerospace Industries ssociation of America, Inc.

[2] PN-ISO 10791-7. (2000P). Test conditions for machining centers, Accuracy of a finished test piece

[3] Bossoni S. (2010). Geometric and Dynamic Evaluation and Optimization of Machining Centers, Dissertation 18383, ETH Zurich

[4] ISO/DIS 10791-7. Test conditions for machining centers - Part 7: Accuracy of a finished test piece, Document ISO/TC 39/SC 2, 2012-02-14

[5] Takeshima H. \& Ihara Y. (2009). Finished Test Piece Example for Five-axis Machining Centers, The 5th Int. Conf. on Leading Edge Manufacturing in 21st century (LEM21), pp.123-126, Osaka, Japan

[6] Bossoni S.; Knapp W. \& Wegener K. (2009). Test piece for 5-axis machining centers, The Proceedings of MTTRF 2009 Annual Meeting

[7] Ibaraki S.; Sawada M.; Matsubara A. \& Matsushita T. (2010). Machining tests to identify kinematic errors on fiveaxis machine tools, Precision Engineering, Volume 34, Issue 3

[8] Gebhardt M.; Knapp W. \& Wegener K. (2012). 5-Axis Test-Piece - Influence of Machining Position, The Proceedings of MTTRF 2012 Annual Meeting

[9] Kotas T. (2012). Testing of accuracy CNC machine tools, Engineering diploma thesis, Institute of Mechanical Technologies, Faculty of Mechanical Engineering and Computer Science, Czestochowa University of Technology, Poland

[10] Adamczak, S.; Stepien, K. S. \& Zmarzly, P. (2017). An analysis of strategies of measurement of 3D rotary elements, Proceedings of the 28th DAAAM International Symposium, pp.1096-1100, B. Katalinic (Ed.), published by DAAAM International, ISBN 978-3-902734-11-2, ISSN 1726-9679, Vienna, Austria

[11] Adamczak, S.; Janecki, D.; Stepien, K. S. \& Wrzochal, M. (2017). An analysis of contemporary methods for measurement of form errors of spherical machine parts, Proceedings of the 28th DAAAM International Symposium, pp.1101-1107, B. Katalinic (Ed.), Published by DAAAM International, ISBN 978-3-902734-11-2, ISSN 1726-9679, Vienna, Austria 